Jurnal Widya Sastra Pendidikan Agama Hindu, Vol 4, No. 1, 2021

ISSN: 2656-7466

\title{
MAKNA PENGGUNAAN KOBER GANESHA SAAT UMAT HINDU MELAKSANAKAN TAWUR KESANGA
}

\author{
I Dewa Gede Ngurah Diatmika \\ STKIP Agama Hindu Singaraja
}

\section{ABSTRAK}

Penyembahan Dewa Ganesha oleh umat Hindu memiliki makna yang beragam. Di antara makna yang beragam tersebut, penggunaan kober Ganesha saat tawur kesanga memiliki makna tersendiri. Makna yang pertama adalah berkaitan dengan peran Ganesha sebagai avighnasvara, yakni makna untuk mengusir atau menolak bhuta kala yang ada di sekitar pekarangan rumah. Ini merupakan alasan riil penggunaan kober Ganesha saat melaksanakan tawur kesanga di Lebuh. Makna yang kedua adalah makna penyucian atau membersihkan makrokosmos maupun mikrokosmos dengan air dan atau sesuatu yang disimbolkan dengan air maupun sarana pembersih lainnya, yaitu cakra dan gada atau bahkan Ganesha itu sendiri.

Kata kunci: Ganesha, tawur kesanga, avighnasvara, dan penyucian.

\section{Pendahuluan}

Perubahan zaman dari satya yuga atau zaman keemasan menuju kali yuga atau zaman kehancuran, merupakan kenyataan, di mana ajaran kebenaran dan kesadaran sebagai manusia beragama menjadi makin berkurang, seiring dengan bertambahnya manusia dan perubahan zaman. Pada akhirnya manusia akan merasa bahwa pada suatu zaman yang sudah renta, ketika kerusakan moral dan pergeseran budaya sudah bertambah parah, maka sudah saatnya alam semesta ini akan kiamat. Itulah yang diperkirakan akan terjadi pada akhir masa kali yuga.

Bahkan Suhardana (2009) menyatakan masa kali yuga merupakan zaman yang tepat untuk kiamat, sebagaimana diuraikan dalam kitab Wisnu Purana. Pada masa kali yuga, ada banyak aturan yang saling bersaing, bahkan bertentangan satu sama lain. Kekerasan, kepalsuan, dan tindak kejahatan akan menjadi santapan sehari-hari. Kesucian dan budi baik perlahan-lahan akan merosot. Gairah dan nafsu menjadi pemuas hati di antara pria dan wanita. Wanita akan menjadi objek yang memikat nafsu birahi. Kebohongan akan digunakan untuk mencari nafkah. Orang-orang terpelajar akan terlihat lucu dan aneh. Hanya orang-orang kaya (kapitalis) yang akan berkuasa.

Kajian Suhardana di atas, sebetulnya sangat sehaluan dengan pendapat Wiana (2009). Menurutnya, gairah dan nafsu merupakan sifat dari awidya. Awidya merupakan sifat-sifat gelap karena rendahnya pemahaman akan pengetahuan suci atau jnyana. Orang bisa gelap dan mabuk karena kaya, karena berkuasa, karena pintar, karena tampan, karena keturunan 
Jurnal Widya Sastra Pendidikan Agama Hindu, Vol 4, No. 1, 2021 ISSN: 2656-7466

bangsawan atau karena memiliki kekuatan (power). Asmita adalah sifat yang menyebabkan manusia sombong dan mementingkan diri sendiri. Raga adalah sifat-sifat yang mendorong manusia mengumbar hawa nafsu. Dwesa adalah sifat-sifat pemarah, benci, dan dendam. Terakhir adalah abhiniwesa, yaitu sifat-sifat yang membawa hidup manusia selalu ketakutan karena keterikatannya pada kehidupan duniawi ini. Yang paling ditakuti adalah sakit dan mati. Untuk memenangkan sifat citta (yang menimbulkan terjadinya kedewaan) agar dapat menguasai sifat klesa (yang menimbulkan terjadinya keraksasaan), agama Hindu menunjukkan berbagai cara yang bernuansa tatwa, susila, dan upacara. Perayaan nyepi dan peringatan tahun baru Saka itu dilakukan untuk membangkitkan kesadaran umat Hindu dalam memenangkan sifat citta atas sifat klesa, sebagai sarana menghindari kehidupan yang papa.

Puncak dari hari raya nyepi adalah pelaksanaan taur kesanga. Taur kesanga tergolong upacara bhuta yadnya. Upacara bhuta yadnya tersebut juga disebut mecaru. Caru artinya harmonis atau cantik. Jadi, tujuan bhuta yadnya itu adalah untuk mengharmoniskan hubungan manusia dengan alam lingkungannya. Setiap pelaksanaan tawur kesanga atau mecaru selalu disertai dengan kober Ganesha. Penggunaan kober Ganesha pada tawur kesanga bukanlah merupakan suatu kebetulan, tetapi suatu hal yang sarat dengan makna.

Penggunaan kober Ganesha juga dapat dibandingkan saat perayaan hari raya nyepi tahun 1921 saka yang jatuh pada tanggal 17 Maret 1999 merupakan suatu bentuk ritual yang sangat istimewa, karena diikuti dengan pelaksanaan ritual Tawur Agung Panca Bali Krama dan Bhatara Turun Kabeh di Pura Agung Besakih. Pelaksanaan ritual tersebut mutlak memerlukan seperangkat banten. Salah satu banten yang terpenting adalah catur. Banten ini disebut catur karena melambangkan empat kekuasaan Tuhan yang menyaksikan ritual tersebut, yakni Brahma, Wisnu, Iswara, dan Mahadewa. Berkenaan dengan itu maka aneka perlengkapannya pun harus berwarna empat, yakni merah, hitam, putih, dan kuning yang disusun menuruti pengider-ider, yakni kelod, kaja, kangin, dan kauh. Pada banten catur terdapat pula banten penyerta, antara lain banten gana. Banten ini dipersembahkan kepada Ganesha yang berkedudukan sebagai avighnasvara dan penuntun para dewa. Dengan demikian, terlihat bahwa dalam upacara besar seperti halnya Tawur Agung Panca Bali Krama peranan Ganesha sebagai avighnasvara ternyata tidak bisa diabaikan (Atmadja, 1999).

Berpijak atas kenyataan-kenyataan yang sudah disebutkan, masalah yang akan dikupas pada artikel ini adalah: apakah makna yang tersimpan pada penggunaan kober Ganesha dalam upacara tawur kesanga?

\section{Pembahasan}

\subsection{Upacara Tawur Kesanga}

Setiap tileming kesanga, yaitu pada penanggal satu sasih kedasa dilaksanakan hari raya nyepi. Pada tileming kesanga atau pada bulan mati 
Jurnal Widya Sastra Pendidikan Agama Hindu, Vol 4, No. 1, 2021 ISSN: 2656-7466

sekitar bulan Maret, yaitu peralihan pergantian tahun Isaka (Isakawarsa) adalah hari pengerupukan namanya, diadakan upacara bhuta yadnya untuk menghilangkan unsur-unsur kejahatan yang merusak kesejahteraan umat manusia.

Sebelum hari raya nyepi dirayakan pada tanggal apisan sasih kedasa selalu didahului oleh upacara melasti, nyejer, dan taur kesanga. Makna upacara melasti dan taur kesanga ini dijelaskan dalam lontar Aji Swamandala dan lontar Sunarigama. Kedua lontar tersebut berbahasa Jawa Kuno. Ini artinya, upacara nyepi sudah pernah dilakukan oleh umat Hindu di pulau Jawa dari zaman dahulu. Dalam lontar Sang Hyang Aji Swamandala disebutkan: Melasti ngarania ngiring prewatek Dewata anganyutaken laraning jagat, papaklesa, letuhing Bhuwana. Artinya: melasti adalah meningkatkan bhakti, menghanyutkan atau menghilangkan papaklesa, dan kotoran alam semesta. Sedangkan lontar Sunarigama menyebutkan tujuan melasti sebagai berikut. Amet sarining amertha kamandalu ring telening segara. Artinya: mengambil sari-sari kehidupan di tengah samudera.

Menurut Wiana (2009), berpijak atas kutipan lontar Sang Hyang Aji Swamandala tersebut, upacara melasti memberikan empat langkah dalam hidup ini menjadi bermakna (meaningful life) untuk mendapatkan sari-sari kehidupan. Keempat langkah tersebut adalah:

1. Ngiring prawatek Dewata.

Ngiring prawatek Dewata artinya membangun sikap untuk senantiasa menguatkan sraddha dan patuh pada tuntunan para Dewata (sinar suci Tuhan). Teks lontar Sang Hyang Aji Swamandala inilah yang dijadikan landasan oleh umat Hindu di Bali melakukan upacara melasti dengan melakukan pawai keagamaan yang di Bali disebut 'mapeed' atau 'mekiis' untuk melakukan perjalanan suci menuju sumber air, seperti laut dan sungai atau mata air lainnya yang dianggap memiliki nilai sakral secara keagamaan Hindu. Peserta melasti umumnya Pura Kahyangan yang ada di lingkungan Desa Pakraman dan sekitarnya lengkap dengan umat penyungsungnya.

2. Anganyutaken laraning jagat.

Angayuntaken laraning jagat artinya dengan upacara melasti kita dimotivasi secara ritual untuk membangkitkan spiritual kita untuk berusaha menghilangkan laraning jagat. Kata lara dan jagat sudah sangat dipahami oleh umat Hindu di Bali. Lara ini agak mirip dengan hidup menderita. Cuma yang disebut dengan lara tidaklah semata-mata orang yang miskin materi.

Banyak juga orang kaya, orang berkuasa, orang yang berpendidikan tinggi, keturunan bangsawan hidupnya lara. Orang kaya menggunakan kekayaannya untuk membangkitkan kehidupan yang mengumbar hawa nafsu. Kekuasaan dijadikan media untuk mengembangkan ego untuk bersombong-sombong ria, atau menggunakan kekuasaan untuk mengeruk keuntungan pribadi bukan untuk mengabdi pada mereka yang menderita.

Demikan juga banyak ilmuwan menjadi sombong karena merasa diri pintar. Banyak juga orang yang meninggi-ninggikan kawangsaannya. Sifatsifat yang negatif itulah yang akan menimbulkan disharmonis dalam 
Jurnal Widya Sastra Pendidikan Agama Hindu, Vol 4, No. 1, 2021 ISSN: 2656-7466

kehidupan bermasyarakat. Jadi, menghilangkan laraning jagat hendaknya diaktualisasikan untuk menghilangkan sumber penderitaan masyarakat, baik yang bersifat niskala maupun yang bersifat sekala.

3. Anganyutaken papa klesa.

Para Pinandita maupun Pandita dalam mengantarkan upacara keagamaan Hindu selalu mengucapkan mantram: Om papa klesa winasanam. Arti mantram ini adalah ya Tuhan semoga papa klesa itu terbinasakan. Hidup yang 'papa' disebabkan oleh sifat-sifat klesa yang mendominasi diri pribadi manusia. Mengenai klesa sebagai lima kekuatan negatif yang dibawa oleh unsur predana sudah diterangkan pada bagian pendahuluan. Lima klesa (-yakni awidya, asmita, raga, dwesa, dan abhiniwesa) inilah yang harus diatasi agar jangan hidup ini menjadi papa. Hidup yang papa itu adalah hidup yang berjalan jauh di luar garis dharma yang membawa orang makin jauh dari Tuhan.

4. Anganyutaken letuhing bhuwana.

Bhuwana yang 'letuh' adalah alam yang tidak lestari. Letuh artinya kotor lahir batin. Atau dalam istilah Sarasamuscaya disebut tidak Bhuta Hita. Bhuta artinya unsur yang ada. Bhuta itu ada lima, yaitu: pertiwi, apah, bayu, teja, dan akasa. Lima unsur alam itulah yang wajib kita jaga kesejahteraannya dan tidak boleh diganggu kelestariannya. Jadi, upacara melasti itu adalah untuk menanamkan nilai-nilai filosofis tersebut, sehingga setiap orang termotivasi untuk melakukan empat langkah tersebut dalam hidupnya secara sadar dan terencana.

Upacara melasti ini dilakukan beberapa hari sebelum upacara taur kesanga. Upacara melasti ini dilakukan oleh berbagai kelompok umat yang memiliki sungsungan Pura. Simbol-simbol sakral seperti Pretima atau Pecanangan dari para Dewata manifestasi Tuhan yang dipuja di suatu pura tersebut berkumpul di Pura Desa dan simbol-simbol sakral itu disthanakan di Bale Agung Pura Desa Adat bersangkutan. Pada saat telah ditentukan secara berpawai, yang di Bali sering dikenal dengan 'mapeed' semua simbolsimbol sakral itu diusung dari Pura Desa menuju sumber air seperti laut, sungai maupun danau. Pada sumber air itulah upacara puncak melasti dilangsungkan dengan inti upacara menghaturkan bhakti pada Tuhan dalam manifestasinya sebagai Dewa Baruna dan terakhir nunas tirtha wangsuhpada sebagai simbol tirtha amertha kamandalu yang didapatkan di tengah segara.

Tujuan upacara melasti itu sebagai media sakral untuk memvisualkan proses hidup untuk memperoleh kehidupan yang sejahtera lahir dan batin di bumi ini sebagai media untuk mencapai moksha. Ini artinya dengan empat langkah itulah umat baru dapat dibenarkan memperoleh hidup yang sejahtera.

Dalam lontar Sunarigama dinyatakan sebagai upaya mengambil air kehidupan yang disebut amet sarining amertha kamandalu ring telenging segara. Pernyataan ini memberi tuntunan bahwa manusia berhak mendapatkan amertha kamandalu apabila telah melakukan empat hal seperti yang dinyatakan dalam lontar Aji Swamandala tersebut. Dari uraian tersebut 
Jurnal Widya Sastra Pendidikan Agama Hindu, Vol 4, No. 1, 2021 ISSN: 2656-7466

dapat dipahami bahwa untuk meraih air kehidupan yang sejahtera lahir batin terlebih dahulu tingkatkanlah sraddha bhakti pada Tuhan yang divisualkan secara sakral dalam upacara melasti. Kuatnya sraddha bhakti pada Tuhan dijadikan pendorong meningkatkan social care yang disebut anganyutaken laraning jagat, perbaikan kualitas diri dengan melepaskan lima kekotoran diri yang disebut papa klesa itu dan juga letuhing bhuwana atau menghilangkan sikap hidup yang merusak alam.

Selesai upacara melasti di laut atau di sungai maupun danau simbolsimbol suci itu kembali diusung ke Pura Desa dan disthanakan di Bale Agung Pura Desa secara bersama-sama. Setelah melasti dilanjutkan dengan upacara nyejer. Upacara nyejer itu dilakukan dengan terus mensthanakan simbol-simbol suci seperti pretima, pecanangan dengan segala kelengkapannya berkumpul di Pura Desa atau di Bale Agung Pura Desa. Setiap hari selama nyejer dihaturkan sesaji dan dengan memperbarui bantenbanten yang telah ada. Umat tiap hari bersembahyang ke Pura Desa dengan arah sembahyang pada pretima atau pecanangan dengan simbol-simbol kelengkapannya sebagai lambang sthana watek Dewata manifestasi Tuhan Yang Mahaesa.

Kata nyejer berasal dari kata 'jejer' yang artinya tegak tak tergoyahkan. Jadi, tujuan nyejer sesungguhnya membangun sraddha dan bhakti yang tangguh atau jejer pada Tuhan. Kalau keyakinan pada Tuhan demikian tegak dan teguhnya, maka godaan demi godaan akan dapat diatasi dengan baik dan benar. Karena manusia itu sering lupa maka setiap sasih kesanga dalam rangka upacara melasti dan taur kesanga umat Hindu diingatkan kembali agar selalu nyejer, artinya menegakkan keyakinan dan bhaktinya pada Tuhan sebagai kekuatan dasar dalam menghadapi dinamika kehidupan ini.

Dalam tradisi Hindu di India ada istilah akanda bajan, yang artinya memuja Tuhan terus-menerus. Akanda bajan ini maknanya sama dengan nyejer. Cuma pelaksanaannya agak berbeda sedikit. Kalau akanda bajan, pemujaan Tuhan dilakukan dengan mengidungkan nama-nama Tuhan terusmenerus. Ada akanda bajan dilakukan selama 12 jam, ada yang 24 jam, bahkan ada yang sampai tiga hari pemujaan dilakukan terus-menerus. Ada juga yang dilakukan secara bergantian. Misalnya, 100 orang diatur mengidungkan nama-nama Tuhan selama lima jam, kemudian lima jam berikutnya diganti oleh 100 orang berikutnya. Demikian seterusnya (Maharani, 2008).

Setelah nyejer, umat Hindu melanjutkan upacara taur kesanga, atau disebut juga mecaru. Mecaru itu merupakan upacara bhuta yadnya. Tujuan caru dalam taur kesanga adalah menjaga keharmonisan hubungan antara manusia dengan alam lingkungannya. Dalam Iontar Agastia Parwa disebutkan: Bhuta yadnya ngarania taur muang kapujan ring tuwuh. Artinya: Bhuta yadnya adalah mengembalikan dan melestarikan tumbuh-tumbuhan (Sutama, 2010).

Jadi, makna bhuta yadnya adalah untuk menumbuhkan keseimbangan jiwa antara mengambil dan mengembalikan. Setiap hari manusia mengambil 
Jurnal Widya Sastra Pendidikan Agama Hindu, Vol 4, No. 1, 2021 ISSN: 2656-7466

berbagai sumber-sumber alam seperti air, tanah, api, udara yang sehat, dan akasa. Hendaknya setelah mengambil itu jangan lupa mengembalikannya agar kembali lestari dan kemudian untuk diambil lagi demi memelihara kelangsungan hidup ini. Jangan hanya memanfaatkan saja tanpa ingat untuk kembali membudidayakannya sehingga tidak punah. Alam semesta ini sesungguhnya badan jasmani Hyang Widhi. Dengan butha yadnya maksudnya suatu yadnya untuk merawat badan jasmani Tuhan yang berbentuk alam semesta ini. Karena itu tujuan hidup mencapai dharma, artha, kama, dan moksha baru bisa dilaksanakan kalau alam ini lestari atau bhuta hita. Hal ini ditegaskan bahwa taur kesanga yang diselenggarakan setiap tilem kesanga dengan upacara bhuta yadnya dari tingkat rumah tangga, lingkungan banjar, desa sampai ke tingkat pusat merupakan bentuk upacara bhuta yadnya. Pusat untuk di Bali dilakukan taur agung di Denpasar ibukota daerah Bali. Pada waktu taur agung ini memuja tiga orang pandita, yaitu pandita Siwa, Budha, dan Bujangga.

Dalam taur kesanga tersebut digunakan banten caru di tingkat merajan (sanggah) berupa banten pejati dan di natar pelinggih menghaturkan segehan agung cacahan 11 atau 13 tanding dan dipersembahkan kepada Sang Hyang Bhuta Buchari. Pada tingkat halaman rumah digunakan banten berupa: segehan manca warna sembilan tanding dengan olahan ayam brumbun disertai tetabuhan tuak, arak, berem, dan air dari desa setempat, dihaturkan kepada Sang Bhuta Raja dan Sang Kala Raja. Sedangkan di lebuh digunakan banten berupa: segehan nasi cacah 108 tanding dengan ulam jeroan matah dilengkapi segehan agung serta tetabuhan tuak, arak, berem, dan air dari desa setempat. Dihaturkan kepada Sang Bhuta Kala dan Sang Kala Bala. Untuk banten di lebuh ini, di Desa Banjarasem terjadi keunikan, yakni ditambah dengan banten gana, yang ditujukan pada Dewa Ganesha. Mengingat caru yang dihaturkan di lebuh dilengkapi dengan kober Ganesha. Sebetulnya, kober Ganesha yang digunakan pada caru di lebuh inilah yang menjadi pusat kajian pada makalah ini.

Sehari setelah upacara taur kesanga, yaitu tanggal apisan sasih kedasa umat Hindu memulainya dengan nyepi. Makna nyepi adalah menyepikan indria, jangan sampai bergejolak untuk dipuaskan terus. Karena berbagai penelitian menyatakan, indria yang dikendalikan tidak diumbar untuk memperoleh kepuasan dapat meningkatkan kesehatan jasmani dan rohani. Untuk mengendalikan indria itu diingatkan agar setiap tanggal apisan atau penanggal satu pada sasih kedasa untuk menyepikan gejolak indria agar ia bergerak secara wajar dan sehat. Indria yang bergerak wajar dan benar itu adalah indria yang patuh pada kendali pikiran. Pikiran berada di bawah kesadaran budhi.

Dalam pelaksanaan hari raya nyepi, umat Hindu diwajibkan melaksanakan catur berata penyepian, yaitu: (1) amati geni (tidak menyalakan api). Tujuannya untuk melakukan pengendalian diri dari segala yang berkaitan dengan emosi, seperti amarah, ambisi, nafsu, dan lain-lain, (2) amati karya (tidak melakukan pekerjaan). Tujuannya untuk 
Jurnal Widya Sastra Pendidikan Agama Hindu, Vol 4, No. 1, 2021 ISSN: 2656-7466

mengendalikan agar tidak melakukan tindakan yang sia-sia bahkan berbuah dosa, (3) amati lelungaan (tidak bepergian). Tujuannya untuk tidak membuat pikiran kita kacau dan berlari ke mana-mana, dan (4) amati lelanguan (tidak menikmati hiburan), dalam artian menghindari diri dari kegiatan yang menyebabkan kita 'lupa diri' (Wiana, 2009).

Menurut Peradnyan (2006), sebetulnya dalam menjalankan catur berata penyepian, tujuan sentralnya adalah mengendalikan empat racun yang ada dalam diri manusia. Keempat racun tersebut adalah pesta meriah merupakan racun bagi si miskin, makanan yang tidak tercerna oleh perut adalah racun bagi tubuh, perawan jelita adalah racun bagi lelaki tua penuh nafsu, dan pengetahuan Weda yang tidak dipraktikkan adalah racun bagi orang yang mempelajarinya.

\subsection{Kober Ganesha dan Taur Kesanga}

Sudah disebutkan sebelumnya, bahwa pada upacara taur kesanga di lebuh, selain menggunakan caru taur kesanga juga dilengkapi banten gana. Banten gana ini dipersembahkan pada Dewa Ganesha. Hal ini disebabkan oleh saat melaksanakan taur kesanga di lebuh selalu dilengkapi dengan kober Ganesha. Manusia yang termasuk golongan tahu di tahunya, pasti bertanya-tanya, apa makna dari penggunaan kober Ganesha saat melaksanakan taur kesanga di lebuh.

Sebetulnya bila disimak secara mendalam, setiap penggunaan sesuatu dalam ritual yang dilaksanakan oleh umat Hindu pasti memiliki makna tertentu. Misalnya, penggunaan air kelapa gading untuk mebanyu awang memiliki makna agar pikiran kita sebelum melakukan persembahyangan bersih dari segala noda.

Unsur-unsur yang terdapat pada kober Ganesha pada dasarnya merupakan simbol-simbol keagamaan. Simbol-simbol itu memuat suatu pemikiran keagamaan yang dimiliki oleh masyarakat pendukungnya. Simbol berfungsi sebagai sarana membantu bagi jiwa yang sedang melakukan pemujaan untuk memahami dan mengungkapkan realitas spiritual, yakni Tuhan Yang Maha Kudus yang tidak mungkin bisa didekati secara langsung, karena Tuhan bersifat transenden, sedangkan manusia adalah makhluk yang bersifat temporal yang terikat di dalam dunianya. Karena itulah, manusia .memerlukan simbol guna mengaktualisasikan gagasannya.

Berkenaan dengan itu, maka keseluruhan aspek yang terdapat pada kober Ganesha adalah bersifat sarat makna. Dengan mengacu kepada pendapat Winangun (1990), pemaknaan atas simbol-simbol yang terdapat pada kober Ganesha, yakni Ganesha beserta aneka senjata dewa-dewa, baik yang dipegang maupun yang mengelilingi Ganesha, mempunyai dimensi posisional. Dalam artian, pemaknaannya tidak terlepas dari simbol-simbol lainnya, termasuk di dalamnya sesajen yang dipersembahkan pada ritual tersebut, dan juga dengan tujuan ritual tawur kesanga maupun caru Roghasangharbhuminya, yakni menyucikan makrokosmos dan mikrokosmos serta nyomia bhuta kala, sehingga manusia bisa hidup dalam suasana 
Jurnal Widya Sastra Pendidikan Agama Hindu, Vol 4, No. 1, 2021 ISSN: 2656-7466

kesucian dan kedamaian dalam rangka mewujudkan kesejahteraan hidup mereka.

Pemakaian kain putih sebagai bahan dasar pembuatan kober Ganesha tidak saja berlandaskan pada alasan teknis, yakni warna putih mudah dikontraskan dengan warna dasar hitam yang memang mudah didapat baik dari bahan baku yang tersedia di alam maupun alat-alat tulis, tetapi yang lebih penting adalah terkait dengan makna kesucian. Penekanan pada aspek kesucian amat penting karena merupakan ciri yang membedakan antara perilaku keagamaan dan non-keagamaan. Perilaku keagamaan, termasuk di dalamnya alat yang digunakan dalam sistem ritual selalu terkait dengan kesucian, sedangkan perilaku non-keagamaan adalah bersifat profan. Karena itu, tidak mengherankan jika penulisan gambar Ganesha mensaratkan pada kain berwarna putih, sebab pemakaian kober Ganesha adalah bertalian dengan perilaku keagamaan. Kober Ganesha berfungsi sebagai simbol atau nyasa guna menunjukkan bahwa dalam ritual itu dilakukan pemanggilan dan pemujaan terhadap Ganesha guna dimohonkan berkahnya, sesuai dengan tujuan ritual yang mereka canangkan.

Senjata cakra yang dibawa Ganesha mengingatkan kepada senjata Wisnu. Pemakaian senjata ini memang bisa dibenarkan, karena sesuai dengan penggambaran Ganesha dalam Mahabharata, yakni berwajah kuning bertangan empat, masing-masing memegang sekuntum bunga teratai, cakra, dan gada. Pemakaian cakra pada tangan kanan Ganesha sebagaimana terlihat pada kober Ganesha tampaknya merupakan suatu simbol yang mencerminkan adanya penguatan yang dilakukan oleh Wisnu atas fungsi Ganesha sebagai penghalang terhadap malapetaka yang bersumberkan pada ulah bhuta kala sebagaimana yang dilakukan oleh awataranya terhadap Duryodhana dan Rawana beserta kawan-kawannya.

Gambar Ganesha dibuat sedemikian rupa, yakni dikelilingi oleh bulatan yang dibuat berlekuk-lekuk dengan garis-garis pendek. Penggambaran ini mungkin dimaksudkan sebagai simbol dari sinar. Hal ini tampaknya dimaksudkan untuk lebih menegaskan bahwa Ganesha pada hakikatnya adalah div, dewa atau sinar suci Ida sang Hyang Widhi Wasa. Sinar suci yang dipancarkannya memiliki daya magis yang meresap ke seluruh penjuru guna memberikan perlindungan atau pengayoman kepada manusia, paling tidak pada areal di mana kober Ganesha dipasang oleh penyelenggara ritual.

Di atas Ganesha terdapat trisula, yakni senjata Siwa (Nala, 1993). Pemakaian senjata trisula tidak saja dimaksudkan untuk menunjukkan bahwa Ganesha adalah putra Siwa, tetapi juga untuk memperkuat posisinya sebagai avighnesvara. Kehadiran trisula memberikan petunjuk bahwa apa yang dilakukan Ganesha telah didukung oleh Siwa. Dukungan itu amat penting, mengingat bahwa Siwa berstatus sebagai Bhutanatha atau rajanya para bhuta kala. Karena itu, dengan melihat senjata Siwa maka bhuta kala diharapkan menjauh dari lingkungan manusia. 
Jurnal Widya Sastra Pendidikan Agama Hindu, Vol 4, No. 1, 2021 ISSN: 2656-7466

Di sebelah kanan Ganesha terdapat genta atau bajra, yakni senjata Dewa Iswara (Nala, 1993). Genta merupakan simbol makrokosmos. Sesuai dengan sistem kesepadanan yang berlaku pada masyarakat Bali, bahwa makrokosmos bersepadan dengan mikrokosmos, seperti desa adat, rumah, dan manusia. Karena itu, pemasangan genta pada kober Ganesha bermakna untuk menekankan kesemestaan penolakan bala maupun pengelukatan yang dilakukan Ganesha, yakni tidak saja berkaitan dengan makrokosmos, tetapi juga mikrokosmos, seperti: desa, rumah tempat tinggal, dan manusianya.

Di sebelah kiri terdapat gambar panah nagapasa, yakni senjata andalan Mahadewa. Nagapasa sering pula disamakan dengan nagabanda, yakni naga sebagai tali. Dalam Ramayana senjata nagapasa dikenal dengan nama nagastrapasa yang berarti panah ular jerat. Nagastrapasa merupakan senjata andalan Indrajit, putra Rawana. Keampuhan senjata nagapasa adalah menjerat musuh (Windia, 1977). Dengan demikian, pemakaian senjata nagapasa pada kober Ganesha bermakna untuk lebih memperkuat fungsi Ganesha sebagai penghalang bhuta kala, yakni dengan cara menjeratnya sehingga tidak berdaya lagi untuk mengganggu kehidupan manusia.

Senjata lainnya adalah gada yang terletak pada bagian bawah Ganesha. Kehebatan senjata gada dalam mengalahkan kejahatan terlihat dari apa yang dilakukan Bhima. Bhima berhasil mengalahkan musuhmusuhnya termasuk Duryadhana, yakni pahanya remuk, karena terkena pukulan gadanya Sang Bhima.

Sebetulnya yang paling vital, gada adalah senjata Dewa Brahma atau Dewa Api. Api bisa menghancurkan apa saja, termasuk keletehan atau mala. Karena itu, tidak mengherankan jika di Bali sering terlihat bahwa seseorang yang baru pulang dari ngelayat atau mejenukan biasanya meminta pembersihan di dapur dengan cara melemparkan air ke atap dapur. Air itu dipakai membasuhi kepala, sehingga keletehan atau mala menjadi sirna. Pudja (1985) menyatakan bhuta kala pun takut terhadap api. Bahkan, sebagaimana yang berlaku pada masyarakat; di desa adat Banjarasem, yakni mereka percaya bahwa aneka magis hitam pun terkalahkan oleh api. Karena itu, ari-ari bayi yang ditanam pada sebelah kanan pintu ke luar rumah di bagian atasnya selalu diterangi lampu yang bahan bakarnya minyak tanah selama 45 hari setiap malam. Hal ini bertujuan agar bayi tidak diganggu oleh pengaruh magis hitam (Aryana, 2006). Dengan demikian, penampilan gada pada kober Ganesha secara otomatis ikut memperkuat fungsi Ganesha baik sebagai penolak bala maupun pengelukat.

Apabila keseluruhan senjata yang tersurat pada kober Ganesha, yakni trisula, cakra, genta, nagapasa, dan gada, lalu dikaitkan dengan pemiliknya, yakni Siwa, Wisnu, Iswara, Mahadewa, dan Brahma, maka dilihat dari segi unsurnya memperlihatkan kesamaan dengan dewa-dewa yang dipuja pada banten catur. Sejalan dengan itu, maka empat senjata dalam kober pada hakikatnya bermakna pula untuk menyimbolkan empat kemahakuasaan Tuhan atau Siwa. Karena itu, gagasan yang tampaknya ditonjolkan pada 
Jurnal Widya Sastra Pendidikan Agama Hindu, Vol 4, No. 1, 2021 ISSN: 2656-7466

kober Ganesha adalah bukan tata letak atau pengider-ider, melainkan unsur kemahakuasaan Tuhan dalam kaitannya dengan penyucian tiga komponen utama dari Panca Mahabhuta, yakni air, udara, dan tanah. Hal ini sejalan dengan apa yang dikemukakan Ganapati Tattva bahwa Wisnu memelihara air, Iswara berstatus sebagai pemelihara udara, sedangkan Brahma berstatus sebagai pemelihara tanah.

Penyucian maupun penangkalan marabahaya secara niskala pada udara, tanah, dan air tidak bisa dilepaskan dari kepercayaan tentang penyebaran penyakit terhadap manusia yang dilakukan oleh Panca Durga. Sebagaimana dipaparkan oleh Nala (1993), Panca Durga yang berstatus sebagai tangan kanan Bhatari Durga bertugas untuk menimbulkan penyakit bagi manusia, yakni dengan cara menyebarkan atau menularkannya melalui udara, air, dan tanah. Penyakit itu menjalar secara niskala, sehingga pengendaliannya pun harus menggunakan cara niskala, yakni ritual yang bersifat religius magis.

\section{Simpulan}

Dari paparan yang sudah dikemukakan, dapat disimpulkan bahwa sumbangan yang diberikan oleh kober Ganesha dalam ritual taur kesanga (berkaitan dengan hari raya nyepi) adalah menyukseskan ritual eliminatio, yakni mengusir setan atau bhuta kala. Selain itu, kober Ganesha juga membantu pencapaian tujuan ritual expiatio, yakni membersihkan makrokosmos maupun mikrokosmos dengan air dan atau sesuatu yang disimbolkan dengan air maupun sarana pembersih lainnya, yaitu cakra dan gada atau bahkan Ganesha itu sendiri.

\section{Daftar Pustaka}

Aryana, Wayan. 2006. Peranan Api Sebagai Penolak Bhuta Kala. Surabaya: Paramita.

Atmadja, Nengah Bawa. 1999. Ganesha Sebagai Avighnesvara, Vinayaka, dan Pengelukat. Surabaya: Paramita.

Maharani, Nyoman. 2008. Nyepi dan Maknanya Bagi Umat Hindu. Denpasar: Percetakan Bali Post.

Nala, Ngurah. 1993. Usada Bali. Denpasar: Upada Sastra.

Peradnyan, Ida Bagus. 2006. Nyepi Berlandaskan Kitab Suci Veda. Surabaya: Paramita.

Pudja, G. 1985. Pengantar Agama Hindu Jilid I untuk Perguruan Tinggi. Jakarta: Mayasari. 
Jurnal Widya Sastra Pendidikan Agama Hindu, Vol 4, No. 1, 2021 ISSN: 2656-7466

Suhardana, K.M. 2009. Roga Sanghara Bhumi: Jika Dunia ini Mengalami Malapetaka dan Cara Mengatasinya. Surabaya: Paramita.

Sutama, Ketut. 2010. "Upacara Taur Kesanga Sebagai Upaya Penyeimbangan Alam Semesta." Makalah yang Disampaikan dalam Seminar IImiah di Disdikpora Bali, Tanggal 25 Juni 2010.

Wiana, I Ketut. 2009. Makna Hari Raya Hindu. Surabaya: Paramita.

Winangun, Y.W.W. 1990. Masyarakat Bebas Struktur Liminitas dan Komunitas Menurut Victor Turner. Yogyakarta: Kanisius.

Windia, I Gusti Nyoman. 1977. Ramayana. Denpasar: Guna Agung. 